\title{
20 años sin Nina S. de Friedemann. Un acercamiento al estudio antropológico de las comunidades afrodescendientes en Colombia*
}

DOI: https://doi.org/10.18046/recs.i32.3726

\author{
20 Years without Nina S. de Friedemann. \\ An Approach to the Antropological Study of Afrodescendent \\ Communities in Colombia
}

\author{
Peter Rondón-Vélez ${ }^{* *}$
}

Instituto Caro y Cuervo (Bogotá, Colombia)

\begin{abstract}
* Este artículo de investigación es un resultado del proyecto "Memoria, activismo y academia. Agencias situadas: 40 años del Primer Congreso de la Cultura Negra de las Américas-2O años sin Nina S. de Friedemann”. En agosto de 2017 se cumplieron cuatro décadas del congreso celebrado en Cali y organizado por Manuel Zapata Olivella (1920-2004), el cual contó con la participación de la antropóloga bogotana que estaba trabajando en Ma Ngombe: guerreros y ganaderos en Palenque (1979). Financiada por la Dirección General del Instituto Caro y Cuervo, la investigación evidenció las redes creadas a partir de los dos intelectuales y sus formas de agenciamiento, en tanto estrategia para visibilizar su activismo, producción académica y literaria. El presente texto amplió su aparato crítico y anecdótico con las conferencias del encuentro "Conversaciones: 20 años sin Nina" (29 y 30 de octubre de 2018); el evento fue organizado por Carmen Millán, Jaime Arocha, Alberto Abello Vives y Peter Rondón Vélez, con el apoyo del Instituto Caro y Cuervo, la Biblioteca Luis Ángel Arango, el Grupo de Estudios Afrocolombianos-Universidad Nacional y la Universidad del Valle. Artículo de investigación recibido el 23.04.2019 y aceptado el 20.12.2019.
\end{abstract}

** Magíster en Literatura y Cultura del Instituto Caro y Cuervo; Licenciado en Humanidades, Lengua Castellana de la Universidad de Antioquia. Investigador del Grupo de Investigación en Literatura del Instituto Caro y Cuervo. Correo electrónico: peter.rondon@caroycuervo.gov.co ORCID: https://orcid.org/oooo-0oo3-2087-8681 


\section{Cómo citar/How to cite}

Rondón-Vélez, Peter (2020). 20 años sin Nina S. de Friedemann. Un acercamiento al estudio antropológico de las comunidades afrodescendientes en Colombia. Revista CS, 32, 249-277. https://doi.org/10.18046/recs.i32.3726 


\section{Resumen}

El artículo presenta la vida y obra de Nina S. de Friedemann, al destacar la relevancia de sus estudios sobre las culturas negra e indígena en Colombia, y evidenciar su comprensión de términos como identidad, etnia y huellas de africanía. Tomando como punto de partida el Fondo Nina S. de Friedemann, textos inéditos de la revista América Negra y charlas con familiares y colegas, se propone un diálogo entre sus procesos de investigación y algunas de las transformaciones que han vivido, en las últimas dos décadas, las comunidades por las cuales trabajó. Finalmente, se presentan las memorias del evento "Conversaciones: 20 años sin Nina", para destacar la presencia intelectual y el compromiso histórico de mujeres y hombres por consolidar un horizonte de estudio de la tradición cultural afrolatinoamericana.

\section{PALABRAS CLAVE:}

Nina S. de Friedemann, antropología, etnia, identidad, cultura negra

This article presents the life and work of Nina S. de Friedemann. It highlights the relevance of her studies on Black and Indigenous cultures in Colombia, and demonstrates her understanding of terms such as identity, ethnicity, and traces of African presence. Taking as a point of departure the Nina S. de Friedemann Collection, unpublished texts from the journal América Negra, and discussions with family members and colleagues, this proposal entails creating a dialogue between her research processes and several transformations over that last two decades that affected the communities for which she worked. Finally, the memoirs of the event "Conversations: 20 years without Nina" are presented in order to highlight the intellectual focus and historical commitment of women and men in order to consolidate a horizon of study of the Afro-Latin American cultural tradition.

\section{KEYWORDS:}

Nina S. de Friedemann, Anthropology, Ethnicity, Identity, Black culture 



\section{A Alberto Abello Vives, Jaime Arocha \\ y a la familia Friedemann-Sánchez}

Nina S. de Friedemann (1930-1998) fue una antropóloga colombiana que abogó por reconocer los aportes indígenas y negros en la constitución del país; a mediados de los años sesenta, las pesquisas sobre la comunidad negra se reducían a las del jesuita José Rafael Arboleda (1952), Rogerio Velásquez (1957; 1959) y Aquiles Escalante (1954; 1965). Debido al reducido panorama, subsistía la responsabilidad de ampliar las investigaciones y trascender, como ya lo venían haciendo estos académicos, los escenarios de exotismo, danza, música y rito que mantenían vigente un estereotipo e impedían ver la importancia de la cultura negra en la formación de los países de América Latina. En una época donde el trabajo de la mujer no era validado por ciertas esferas científicas, ella se abrió camino asumiendo como pilares de su profesión la ética y el compromiso social que deben asumir los intelectuales a la hora de recoger y analizar datos de una comunidad.

IMAGEN 1 Nina S. de Friedemann en San Basilio de Palenque, acompañada por dos de sus habitantes (1975-1978)

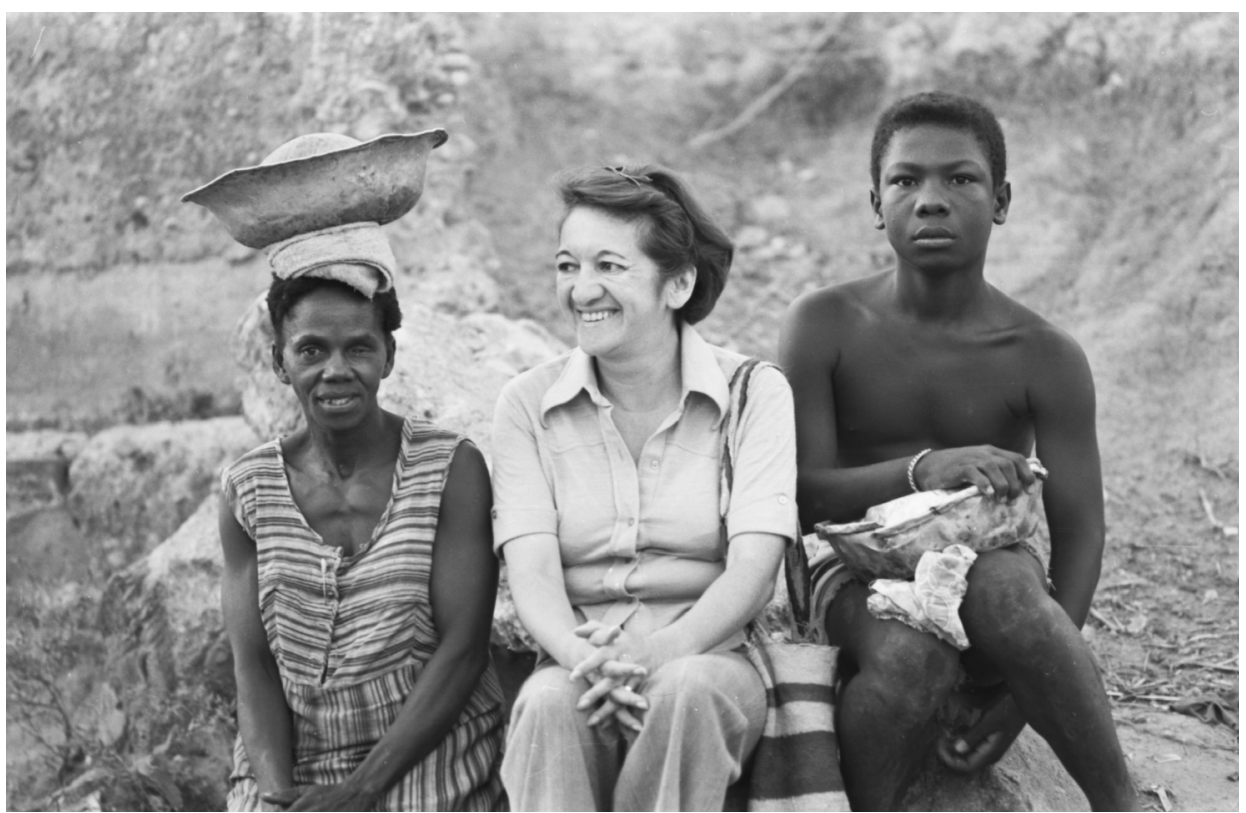

Foto: (c) Richard Cross. Tom \& Ethel Bradley Center (California State University, Northridge, EE. UU.). 
Es ilusorio pensar que puedan darse separaciones entre la formación del antropólogo y sus intereses, las formas como actúa en el terreno o la selección de los temas y paradigmas teóricos que lo atraviesan. De alguna forma, "sus experiencias, sus utopías (...) son cimientos vitales en el ejercicio profesional” (Friedemann, s.f.); por ello, el artículo parte de aquellos deseos que movilizan el espíritu investigativo. Conectar el ámbito personal con el andamiaje conceptual que rodeó su labor permite detallar el universo envuelto en las etapas formativas de una mujer que asumió el compromiso de estudiar y defender la heterogeneidad de Colombia; su discurso, visto en diálogo con las realidades sociales que lo atraviesan y las visiones de mundo ajenas, que se encausan o bifurcan en relación con las suyas, posibilita trascender el entorno académico, acercarse a otras consideraciones teóricas y apuntar los cambios que ha tenido la antropología como ciencia de la cultura.

\section{Nina S. de Friedemann y la investigación antropológica ${ }^{1}$}

Nina S. de Friedemann² nació en Bogotá en 1930, cursó estudios en el Hunter College de Nueva York y en la University of Southern California, donde conoció a Robert Friedemann, psicólogo y artista plástico, con quien contrajo matrimonio en febrero de 1961. A finales de ese mismo año regresó a Colombia y se graduó como antropóloga el 15 de diciembre de 1964, junto a su hermano Liborio Alfonso, en el Instituto Colombiano de Antropología (ICAN), con la tesis Tenencia de tierras, un factor de marginación socioeconómica en una comunidad rural, "El común de indígenas en Churuguaco", realizada entre Tabio y Tenjo, municipios de Cundinamarca (Friedemann, 1965). Después de obtener su título y hacer trabajo de campo en el archipiélago de San Andrés y Providencia, con María Rosa Mallol de Recasens ${ }^{3}$, Nina identificó la

1. Agradezco los consejos de Jaime Arocha, en espacios académicos o conversaciones informales, sus palabras me obsequiaron una imagen crítica, además de la otorgada por los libros, de la trayectoria de Nina. Así mismo, a Greta Friedemann por leer una versión preliminar del artículo y sugerirme cambios. Para claridad del lector, los materiales que mencionaré en adelante pueden consultarse en el Fondo Nina S. de Friedemann (Sala Libros Raros Manuscritos de la Biblioteca Luis Ángel Arango). Desde 2017 soy visitante asiduo de tales archivos y he entablado con ellos un lazo intelectual y afectivo, desde el cual me permito emplear el tono cercano de Nina.

2. Su nombre de nacimiento fue Nina Virginia Sánchez Avella; sin embargo, se desarrolló profesionalmente con el mencionado en el presente artículo. El cambio se debe a la legislación colombiana que, durante buena parte del siglo XX, impuso a las mujeres tomar el apellido de su pareja incluyendo el posesivo "de".

3. El trabajo en el Litoral Atlántico se convirtió en su primer terreno de diáspora e involucró una toma de conciencia frente a tal suceso, en relación con el desarraigo de las comunidades negras de África y su constitución cultural en América. Resultado de esta inmersión son los trabajos Ceremonial religioso funébrico 
carencia de disquisiciones académicas en torno a la presencia africana en Colombia y comprendió la necesidad de subsanar esos vacíos. Es así que viajó a la Universidad Emory, en Atlanta, Georgia (EE. UU.), donde fue investigadora asociada del Center for Research in Social Change desde 1967 y logró ponerse en contacto con colegas y bibliografía pertinente. De esta inmersión en Norteamérica resalta la amistad con Ronald J. Duncan, quien se casó con su hermana Gloria Sánchez.

En 1969, tras regresar a Colombia, inició el proyecto Estudios de negros en zonas auríferas del litoral Pacífico, auspiciado por el Departamento de Antropología de la Universidad Nacional de Colombia y el ICAN, que la llevó a recorrer lugares como Barbacoas o Los Brazos, sobre el río Güelmambí en Nariño, y gracias al cual publicó Güelmambi: formas económicas y organización social (1969). Durante este viaje, sumado a otros que realizó durante los ochenta, escribió diarios de campo donde señala la composición social de las comunidades, sus árboles genealógicos, la ubicación de las casas y el trazado de las calles en la topografía de las regiones ${ }^{4}$.

La obsesión por documentar cada detalle se debió a las enseñanzas paternas. Como anota Jaime Arocha (2006), Liborio Sánchez, ingeniero graduado de la Universidad de Pittsburg y quien participó en la construcción de algunos tramos del ferrocarril paralelo al Magdalena, en las vacaciones llevaba a Nina y a su hermano a recorrer los pueblos cercanos al río. Armados de cuadernos que él les entregaba para anotar con fechas, horas y nombres lo que llamara su atención, esas travesías ampliaron sus visiones y los acercaron a las fiestas religiosas de varias tierras ribereñas ${ }^{5}$. Es así que no fue nuevo para Nina el método de escribir todo lo que veía, al iniciar sus estudios como antropóloga; con los años, aquella acción de la infancia determinó su

representativo de un proceso de cambio en un grupo negro de la Isla de San Andrés (Colombia) (1964-1965) y Miss Nansi, Old Nansiy otras narraciones de folclor de la isla de San Andrés (Colombia) (1967); en el caso de Mallol de Recasens, Dibujo infantily personalidad cultural en la Isla de San Andrés (Colombia) (1967).

4. En 1974, entre los meses de mayo y agosto, conoció, en Bolívar, los municipios de San Basilio de Palenque, Arroyohondo, San Jacinto, San Pablo, así como la península de Barú y el corregimiento Pasacaballos; recorridos documentados en más de cien notas inéditas que reposan en el Fondo Nina S. de Friedemann, y dibujan los cuadros de costumbres y las percepciones raciales en estos poblados. Otros sitios visitados en 198 o fueron Puerto Gaitán (Meta), Ciénaga (Magdalena), Timbiquí (Cauca) y, nuevamente, San Basilio y Cartagena (Bolívar). Cada diario consigna rutas para llegar a los municipios, caseríos o corregimientos, entrevistas y apreciaciones sobre fiestas, gastronomía, minería, pesca, agricultura y actividad artesanal; descripciones que serían el sustrato inicial de publicaciones como Minería, descendencia y orfebrería artesanal. Litoral Pacifico (Colombia) (Friedemann, 1974).

5. En el texto En los terrenos de la diáspora afrocolombiana (Friedemann, s.f.), Nina recuerda cómo su papá le relataba que en EE. UU., en los teatros, medios de transporte y servicios sanitarios, la gente negra era considerada inferior y se enfrentaba a procesos de discriminación físicos e ideológicos. En el mismo artículo, anota que esa cantidad demundo que vivió su padre lo interpeló a reflexionar sobre las condiciones de desigualdad; condiciones que procuró dar a conocer a sus hijos, para invitarlos a pensar la realidad social del país. 
orientación y marcó su ejercicio profesional, caracterizado por hacer escuchar la voz de los pueblos marginados. Su trabajo es uno de los primeros esfuerzos por incluir a las personas de ascendencia africana en la agenda antropológica nacional, y hacer visible cómo se han transformado las dinámicas en el Pacífico y el Caribe durante las últimas tres décadas, a causa de las migraciones generadas por el conflicto armado o el impacto que la minería y los monocultivos han causado en el paisaje, entre otros factores. Las libretas expresan la amalgama teórica de investigaciones destacables por trascender el discurso academicista, situándose lejos del tono seco y objetivo de muchos practicantes de la ciencia social (Patiño-Rosselli; 1999: s.p.), para sumergirse en observaciones de terreno que le otorgan libertad al dato etnográfico, prestan atención al detalle y contienen un arte verbal comprensible para cualquier lector.

Más allá de los informes a los cuales dan lugar manifestaciones culturales dadas, las libretas ejemplifican la relevancia de no resumir un grupo social a objetos observables desde un panóptico y demarcan la importancia de incluir, en la recolección de información y posterior análisis, la voz de quien habita las costumbres motivo de estudio, pues su visión enriquece la interpretación y aporta herramientas necesarias para discernir el sentido de un suceso. Aunque esta perspectiva ha tomado fuerza durante los últimos lustros -pues el testimonio de quien integra un sistema cultural, ejerce o enfrenta condiciones de poder, devela elementos que un observador externo difícilmente evocaría con fidelidad-, la labor de Nina es reveladora al verse en paralelo con trabajos como el de Sidney Mintz (1996) y su reconstrucción de las actividades agrícolas en el Caribe insular o la postura poscolonial de Gayatri Spivak (1998), quienes, a partir de la voz del subalterno, critican las prácticas de invisibilización de las cuales son objeto algunas etnias.

Cuando Nina inició sus estudios, el acento recaía sobre lo indígena, su arqueología y problemas contemporáneos. José Rafael Arboleda, formado a finales de 1940 en la Universidad de Northwestern -donde conoció las posturas de Melville Herskovits (1895-1963)-, autor de Nuevas Investigaciones Afrocolombianas (1952); Aquiles Escalante quien en 1954 publicó El palenque de San Basilio. Divulgaciones Etnológicas y, en 1965, El negro en Colombia (libro resultado de sus estudios en la misma institución de Arboleda), y Rogerio Velásquez con La canoa chocoana en el folclor (1957) o Cuentos de la raza negra (1959), eran quienes iniciaban una rama de la antropología poco explorada para ese momento. En aquel escenario existía una evidente asimetría cuando el trabajo de los mencionados autores era publicado en la Revista Colombiana de Folclor, mientras los demás tenían lugar en la Revista Colombiana de Antropología ; situación debida, seguramente, a que en Colombia: 
Siempre se ha dicho es que el negro es un individuo perezoso y que no trabaja y generalmente el reconocimiento que se le ha hecho al negro es el reconocimiento por su música, por su poesía, por estas cosas que se han venido en llamar folclor. (Friedemann, 1978a: s.p.)

En el país se ha aceptado con menor resistencia hablar de un pasado indígena que se remonta más allá del encuentro de mundos en 1492 (asumimos su existencia aun cuando las condiciones otorgadas por el Estado no les brindan plataformas de desarrollo7). Pero Nina cuestionó si nos enorgullecíamos de tener una historia negra o si conocíamos los avatares experimentados por estas comunidades en su afirmación étnica, y procuró subsanar la resistencia a aceptarla como objeto de estudio.

En Un siglo de investigación social. Antropología en Colombia (Friedemann; Arocha, 1984), se proponen unos períodos en el devenir de las ciencias sociales; herramienta útil para detallar la presencia de lo negro en la antropología. Los autores ubican una primera etapa formativa en el decenio de 1850 cuando la Comisión Coreográfica, dirigida por Agustín Codazzi, inició actividades dedicadas a elaborar el primer mapa nacional, observar y describir la sociedad. Con el cimiento otorgado por los biólogos, cartógrafos, pintores y analistas sociales, el cambio de siglo trajo consigo un período generativo, caracterizado por el arribo al país de "arqueólogos y etnólogos que ya habían recibido un entrenamiento universitario especializado en tales disciplinas" (Friedemann; Arocha, 1984: 6). La polímata bogotana documenta este momento en el capítulo "Ética y política del antropólogo: compromiso profesional”, al reconstruir los hechos que dieron pie a la profesionalización de la antropología en Colombia, con la llegada de Paul Rivet en 1940, por invitación del presidente Eduardo Santos (1938-1942), pasando por la creación del Instituto Etnológico Nacional (IEN), en 1941, y un año más tarde del Instituto Indigenista de Colombia, hasta culminar con la crea-

7. En los últimos años, líderes sociales e indígenas son víctimas de los residuos que dejó el conflicto armado. A pesar del desarme masivo, las disidencias de las FARC y otros grupos violentos han implantado formas de poder, mediadas por la muerte como herramienta de control y miedo, en territorios donde el Estado no consolida una presencia efectiva. El elevado número de asesinatos, los problemas con la tierra y el reconocimiento de los campesinos como sujetos de derecho, ha propiciado ambientes de protesta; por ejemplo, a principios de 2019, cientos de indígenas del Cauca, Nariño, Choco y Putumayo, cerraron vías que paralizaron el sur de Colombia; así mismo, durante los últimos meses del mismo año, miles de personas salieron a las calles de varios departamentos exigiendo acciones estatales que respondieran a las necesidades e intereses de su realidad. En ambos casos, la movilización instó al Gobierno a proponer políticas acordes con la identidad étnica de los pueblos (Restrepo; Ramírez; Murcia, 2019), defender los derechos humanos y solucionar la crisis económica y educativa que aqueja a la nación. Si bien las marchas no estuvieron exentas de controversia por los mecanismos de presión ejercidos y los enfrentamientos con la fuerza pública, este tipo de sucesos manifestó la urgencia ciudadana por señalar los problemas y exigir cambios; clamor que buscaba humildad por parte del Gobierno, para que reconociera sus errores y atendiera las coyunturas de un territorio donde la vida cada vez resulta más frágil. 
ción del ICAN, en 1952, por la fusión del IEN con el Servicio Arqueológico Nacional (1938). Por estos mismos años, un grupo de jóvenes del Caribe y el Pacífico radicados en Bogotá, entre los que resaltan Natanael Díaz, Adolfo Mina Balanta, Marino Viveros, Helcías Martán Góngora y Manuel Zapata Olivella, crearon el Club Negro de Colombia en 1943 y el Centro de Estudios Afrocolombianos en 1947; iniciativas que "harán parte de la historia de la construcción de un sujeto político que alcanzará reconocimiento constitucional en 1991 y de categorías (...) que han ido cambiando de denominaciones con el desarrollo del activismo y la investigación" (Millán de Benavides; Rondón-Vélez, 2019: 59). La obra literaria y crítica de estos escritores, claves al plantear nuevas agendas de estudio, cimentaría un camino de valoración de la cultura negra. No obstante, tal progresismo se vio coartado por la excesiva paranoia hacia movimientos políticos emergentes, que empezó a dominar el continente.

En un camino de idas y venires aparece un período normativo en los años cincuenta, cuando los grupos de investigación procedentes de los institutos etnológico e indigenista se atomizaron y dispersaron, víctimas de la persecución política. "Hubo, entonces, un intento por legitimar tales disciplinas [arqueología y antropología] en la medida en que sustentaran las enseñanzas de la Biblia y el aporte de la cultura española" (Arocha, 1984: 52-53), o siguieran los perfiles definidos por los órganos oficiales. Así mismo, se entorpeció al IEN expulsando a sus principales investigadores bajo la sindicación de ser comunistas; situación que perjudicó al Instituto Indigenista, pues se nutría de los trabajos desarrollados por tales profesionales. Los egresados del Etnológico, Gregorio Hernández de Alba, Graciliano Arcila y Aquiles Escalante, quienes habían fundado filiales de este a finales de 1948 en el Cauca, Antioquia y Atlántico, respectivamente, se vieron obligados a cerrar sus puertas por la creciente violencia. Es de anotar que, a pesar del sombrío panorama, los investigadores, "con el patrocinio de agencias internacionales, (...) viajan al extranjero a especializarse. Regresan a mediados del mismo decenio y se vinculan a planes de desarrollo gubernamentales" (Friedemann; Arocha, 1984: 7).

La fuga y posterior regreso de académicos adviene en un período de tecnocratización durante los primeros años del Frente Nacional, seguido por uno de crítica y conflicto, a finales de los sesenta, que se extendió hasta 1980 cuando se recrudecieron los lineamientos que regían el quehacer antropológico, a tal punto que mientras Álvaro Soto Holguín dirigió el ICAN (1970-1980), los antropólogos vivieron una condición similar a la del intelectual del siglo XIX, al adscribirse, de una u otra forma, a los valores de la época ${ }^{8}$. El Estado se constituyó como uno de los mayores

8. En la ponencia Antropología en Colombia: después de la conmoción, presentada en el Seminario Latinoamericano de Antropología (Brasilia, 22-25 de junio de 1987), Nina amplió lo expresado en el citado ensayo de 1984 y en Bibliografía anotada y directorio de antropólogos colombianos (Friedemann; Arocha, 1979), sobre 
mecenas y contratistas para estudiar la cultura, al tiempo que planteó restricciones improcedentes para una comprensión dinámica de lo que contempla apreciar el espectro humano; escisión en la que el negro no obtuvo atención.

En esta línea de sucesos, el ICAN, resultado de la progresión histórica y las dinámicas acontecidas en varios centros de estudio que le precedieron, consagró espacios diferentes para el estudio de los pueblos: por una parte, los indígenas fueron objeto de la antropología, mientras la gente negra lo era de la folclorología. La división preocupó a Nina; para ella aprender sobre lo indígena no era discutible, pues concebía su importancia en una nación pluralista. Su lucha fue contra la arbitrariedad ejercida por las esferas políticas; ella "rechazaba la negación de la negridad en una sociedad gobernada por la ideología dominante de una identidad nacional mestiza; una ideología que, mientras le daba cabida a lo indígena como una forma institucionalizada de la diferencia (...) ignoraba (...) lo negro" (Wade, 2013: 24).

La ausencia de ciertos temas contrastaba con una postura arbitraria frente a otros. Se quería estudiar el universo (arte y cosmovisión) de las poblaciones ancestrales, pero se desatendía el clamor de personajes como Hernández de Alba, quien en 1936 manifestó "una defensa de la indianidad que se expresó en el interés (...) por la arqueología precolombina y el examen de los indios contemporáneos" (Friedemann; Arocha, 1982: 19); iniciativa que lo convirtió en uno de los pioneros de la antropología y lo llevó a denunciar, en 1950, el genocidio de los paeces (Friedemann; Arocha, 1982: 20). Esta urgencia por salvaguardar a las comunidades de la muerte, la expropiación de tierras y abrir más el espectro del estudio de la cultura contrasta con la posición de Milcíades Chaves, quien, refiriéndose a las condiciones del período normativo, expresó: "No nos dejaron ser antropólogos. Estábamos en el dintel de comenzar a dar, y en ese momento nos truncaron. Nos echaron" (Friedemann; 1984: 395), en referencia a la coacción estatal que por aquellos años parecía ciega al no habilitar otra búsqueda de lo que significa ser indígena o negro, en un país étnicamente diverso, más allá del turismo explotable en zonas como Tierradentro, San Agustín o Ciudad Perdida9 .

El anterior panorama explica por qué hasta hace pocas décadas no fue extraño observar la cultura a partir de elementos biológicos, limitados a incentivar estereotipos, que podían estimular proyectos racistas como los que permearon Europa a mediados del siglo XX, siendo el Nacional Socialismo el de mayor impacto. Este

la gestión de Álvaro Soto, quien, desde su opinión y control personal, estableció un monopolio de lo que podía o no hacerse en el campo antropológico en Colombia.

9. Para comprender las afrentas históricas de la antropología, ver Friedemann y Arocha (1984). Los datos aquí apuntados, fragmentarios en su exposición, acogen mayor cohesión al leer el libro en su conjunto. 
enfoque causó que las etnias africanas y los aborígenes americanos figuraran en una escala de posiciones hacia la adquisición de racionalidad; la biología y la antropología física se centraron en aspectos genéticos y sus cambios en diferentes generaciones, desatendiendo las complejas relaciones que se dan entre los hombres. Anclados en esta perspectiva, los estudios eruditos priorizaron una población:

Los indios se volvieron tema predilecto convirtiéndose en fósiles vivientes del proceso de transformación, en tanto que a los africanos en América, señalados como negros por obra de la trata, se les hizo invisibles dentro de las especificidades de los estudios antropológicos.

Se fue consolidando entonces, una tendencia que mientas por un lado excluía grupos humanos del panorama de su estudio por otro, privilegiaba el examen de mitos y ritos como indicativos del proceso de perfeccionamiento de la razón. Se incurría así, en otra grave exclusión: aquella que permite ver a la cultura como intercambio orgánico entre el ser humano y la naturaleza. (Friedemann; Arocha, 1991:5)

Los científicos sociales asumieron una óptica formalista donde los mitos y las cosmogonías generaron curiosidad, pero los rasgos físicos -un rezago del pensamiento decimonónico que puso el énfasis en la raza y trasladó a lo social planteamientos más próximos al análisis biológico-evolucionista-dominaron la atención y opacaron las contribuciones de diferentes grupos en la formación de nuestra economía, política y cultura. Combatir dicha situación y posicionar ámbitos de exploración que trascendiesen lo biológico, para resaltar la influencia de la comunidad en la que nace un sujeto para constituirse como tal, fue un propósito constante de Nina. En los años sesenta y setenta, cuando eran pocos los autores locales a los cuales recurrir como guía, ella reconoció y documentó las producciones de la cultura negra en la misma vía que Escalante y Arboleda lo hicieron basados en Herskovits o Fernando Ortiz, quienes ya habían emprendido estas acciones en sus países de origen. Teniendo en cuenta ese contexto, no resulta raro que Aquiles Escalante, durante una entrevista en octubre de 1980 (hasta ahora inédita), pronosticara la fecundidad del impulso que empezaba a crecer:

Nina: Cuéntame, [i] qué perspectivas le ves tú a la antropología colombiana?

Escalante: Infinitas como campo de estudio. Si es que no hemos hecho nada (...). Yo le veo un campo infinito porque en realidad en cada cosa apenas estamos comenzando. En el campo de población negra todo está por hacer, uno es porque ahora medio escarbé, lo que estás haciendo tú [Nina] ahora, pero quedan tanto, tanto por hacer en el campo del negro, en el campo de la arqueología, en todos los órdenes [sic]. (Escalante, 1980) 
Durante los siguientes años, Nina publicó Lengua y sociedad en el palenque de San Basilio, en colaboración con Carlos Patiño-Rosselli (Friedemann; Patiño-Rosselli, 1983); Un siglo de investigación social. Antropología en Colombia (ETNO, 1984) que, coeditado con Jaime Arocha, incluyó textos de Xochitl Herrera, Myriam Jimeno Santoyo, Miguel Loboguerrero, Néstor Miranda Ontaneda, Carlos Patiño-Rosselli, Roberto Pineda Camacho y Olga Restrepo; De sol a sol. Génesis, transformación y presencia de los negros en Colombia (Friedemann; Arocha, 1986). En 1991 fundó América Negra y, apoyada en el proyecto Expedición Humana, dirigido por Jaime Bernal Villegas en la Pontificia Universidad Javeriana, dio a conocer escritos de Laurence Prescott, Guillermo Valencia Hernández, Marvin Lewis, Angelina Pollak, entre otros pensadores consagrados a la etnoeducación, el etnodesarrollo y la herencia africana, latente en la vida cotidiana y las letras latinoamericanas. Destaca así la primera editorial:

Para la profunda exclusión que en Colombia han sufrido los grupos negros como tema de estudio a nivel de formación universitaria en el terreno de la antropología, esta apertura de la Expedición Humana es una oportunidad para iniciar el rompimiento de dicha exclusión. Efectivamente, la Expedición ha abierto sus puertas no solo para la investigación, sino que acoge a AMÉRICA NEGRA como un órgano de comunicación entre disciplinas interesadas en estudios de étnicas negras, indígenas y otras poblaciones de Colombia y aquellas que tengan relación con las nuestras. (Friedemann; Arocha, 1991: 6)

En esa nueva etapa que abrió la citada revista, se dio legibilidad a otras expresiones y modos de ser, en línea con agendas de estudio pensadas desde la alteridad históricamente constituida en el país. La discusión sobre la relevancia de lo negro al interior de la escena antropológica pasó a ser una tensión anacrónica, porque si bien faltaba camino por trazar (por ejemplo, finiquitar la discriminación racial en las dirigencias políticas y universitarias), se había logrado su inscripción en las redes de investigación y, poco a poco, se continuaba con acciones afirmativas para su inserción paulatina en los imaginarios colectivos. Los debates profundizaron en el problema de la nominación y se preocuparon por ubicar categorías acordes con las circunstancias del país que debía pensar cómo solucionar las coyunturas sociales, producto de no incluir tempranamente al hombre y la mujer negra en el aparato público. Desatendidos en numerosos escenarios, fue preciso crear articulaciones donde la negridad se asumiera "no sólo en lo que a las categorías de la imaginación teórica y política compete sino también en cuanto a las condiciones desde las cuales se configuran ciertas existencias y experiencias" (Restrepo, 2013b: 9).

La emergencia de lo negro desembocó en formas de apreciar su origen; es así que África como punto cero, centro de la diáspora y el esclavismo, constituía una 
posibilidad entre otras. Las llamadas huellas de africanía, entendidas como el "bagaje cultural sumergido en el subconsciente iconográfico de los africanos esclavizados, que se hace perceptible en la organización social, en la música, en la religión o en el teatro de carnaval de sus descendientes" (Friedemann, 1994: 84), se pusieron en discusión con otras nociones, pues:

Implicaba una forma de escencialismo [sic] que privilegiaba los orígenes africanos como la base de la cultura negra, siendo que la cultura negra colombiana, podría decirse, está formada tanto de insumos de la cultura europea e indígena como de la africana. (Wade, 2013: 26)

La posición de Peter Wade se explica al comprender que ceñir el pasado del hombre negro al África crea una distancia entre este y el territorio que habita, y donde ha gestado una apropiación cultural que pone en diálogo sus raíces con un nuevo espacio. A pesar de ello, las huellas de africanía deben asumirse como una compleja dinámica de creatividad y transformación que, además del concurso de lo africano, comprenden lo europeo y lo aborigen americano. Bajo esta mirada, conciben raíces en otras latitudes, al tiempo que reconocen las prácticas y tradiciones propias, desmarcadas de un puente transatlántico. Corresponde, entonces, leer lo negro como presencia activa de América y, desde allí, afianzar la adherencia con esta comunidad, al igual que sucede con los pueblos ancestrales que asumimos como integrantes de nuestro trasegar histórico.

Para Wade, el enfoque africanista limita cuando algunas personas no empatizan con ese pasado y a veces les resulta problemático reconocerse como negros; una denominación que se complejiza en los contextos urbanos donde la palabra llega a connotar marginalidad. Su postura es paralela a la de Eduardo Restrepo (2013a), para quien las categorías de negro, afrocolombiano, afrolatinoamericano o afrodescendiente implican, más que un cambio de palabras, una asimilación particular de la historia y un ejercicio intelectual por buscar formas de concebir la identidad; confluencia en la cual no se puede obviar el mestizaje o los procesos de blanqueamiento que han coexistido en el país. Al respecto, Mara Viveros (2013: 91) se cuestiona sobre "cómo hacer compatible [en el ambiente latinoamericano] el carácter manifiestamente mezclado de su población con las connotaciones claramente blancas del progreso y la modernidad"; su respuesta a tal inquietud se apoya en la noción de trietnicidad de Manuel Zapata Olivella, un término donde lo blanco, lo negro y lo indígena discuten lo positivo de una formación nacional mestiza y el despropósito de algunos países que buscan borrar las diferencias, al abolir los rasgos distintivos. La posición de Zapata Olivella, por intercesión de la ensayística de Viveros, reconoce en Colombia una constitución híbrida, en la cual se libran tensiones y luchas sociales en continuo cambio. 
Partiendo de la profundidad en los enfoques apuntados, es claro que el nuevo milenio suscitó desplazamientos para lo negro, entendiendo esta categoría como ambigua y maleable. La flexibilidad de los conceptos en pro de su claridad y afirmación epistemológica evidencian cómo Nina posicionó una franja que en el pasado no contaba con el interés general de la antropología, y que fue y es susceptible de promover debates que actualmente coinciden en la importancia de reconocer el aporte de la gente negra. Sin pretender demarcar la validez de las posiciones expuestas, corresponde concebir las diferentes formas de articulación del ser negro como una circulación constante de ideas que cada antropólogo adapta, asume y apropia dependiendo sus formas de percibir el mundo, sin olvidarse de los marcos institucionales $\mathrm{y}$ formaciones disciplinarias que le interpelan a la hora de emprender un proyecto.

A fin de comprender el maremágnum conceptual que cobija el estudio de una comunidad, el espíritu trashumante de Nina la llevó a visitar diferentes países como asistente a congresos, simposios y seminarios, experiencias que la instaron a asumir la responsabilidad de gestionar encuentros para comprender las relaciones entre América Latina y África ${ }^{10}$. Un resultado de los viajes fue la comunicación con profesores e investigadores extranjeros donde planteó dificultades para definir qué es una etnia, la complejidad de pensar ese término y cómo asumir una identidad a partir de lo étnico. Al respecto, destaco el Segundo Congreso de la Cultura Negra de las Américas (Panamá, 1980), y la ponencia Estereotipia y realidad de la identificación del negro colombiano, donde explicó, con sorprendente claridad -la cual aún no definía a etnólogos y etnógrafos del país-, que una etnia "está hecha por gente, pero por gentes que se identifican las unas a las otras con unos elementos (...) que pueden ser de raza, de sociedad y de cultura" (Friedemann, 1980), de lenguaje; elementos compartidos en un espacio y bajo condiciones de vida comunes, que deben interpelar un individuo a asumirse como parte de ella o dimitir de su adscripción:

La identidad étnica es el sentimiento y es la conciencia que tiene un individuo de ser como es, de lucir como es y de actuar como es sin tener vergüenza de ser como es (...). Cuando el individuo está avergonzado, cuando no quiere ser como es entonces está precisamente en situación de alienación y en esa situación es que se ha colocado a muchos negros aquí en Colombia. (Friedemann, 1978a: s.p.)

10. Algunos ejemplos son: Primer Congreso Nacional de Cultura (1966), Primer Congreso de Antropología (Popayán, 1978), IV Congreso Interdisciplinario de la Sociedad y el Caribe (Alemania), $47^{\circ}$ Congreso Internacional de Americanistas (EE. UU., 1991), VII Congreso Internacional. Asociación Latinoamericana de Estudios Afroasiáticos (México, 1992), IX Congreso de Colombianistas (Bogotá, 1995). 
Uno de los problemas que ha impedido el reconocimiento de la diversidad es cómo nombrarla o reconocerla. Es más fácil asumir la mirada del letrado, quien dice si alguien cumple o no con determinadas características, pero la cuestión está en que, al aceptar su postura, admitimos sus claridades, posibles sesgos morales y su valoración de si un conjunto de personas es depositaria de una cultura ${ }^{11}$. El asiento geográfico, los mitos o la vestimenta facilitan la clasificación de los indígenas. El dilema con otros grupos es lo dispersos que se encuentran y la complejidad de identificarlos en un país que ha tendido a homogenizar cuando se integra una cultura mayor: la colombiana. El Gobierno acoge la diversidad -la Constitución Política de 1991 es prueba de ello-, mas la heterogeneidad se desvirtúa en la realidad.

Hasta antes de la Ley 70 de 1993, las comunidades negras no gozaban de un estatuto que les brindase igualdad frente al resto de la sociedad. Un logro de esta normativa fue la promoción de una pedagogía para aceptar y compartir la diferencia, pues si bien el acto de adscripción a una raza puede darse a partir de un nombramiento externo, sentirse parte de una etnia requiere autoidentificarse. De tal forma, un sujeto o grupo solo se entenderá como tal si evidencia una "conjunción de intereses proyectados frente a (...) otra sociedad (...) otro grupo" (Friedemann, 1978a: s.p.); para ser integrante de una comunidad es necesario pensarse más allá de la filiación racial y visibilizar e interiorizar la contribución de ekobios ${ }^{12}$ en los adelantos regionales o continentales.

En Colombia, el problema radica en que prima un estereotipo de persona con ciertas características para establecerse cómodamente, existe una lucha de clases permanente y, en diversas situaciones, un deseo por escalar a mejores condiciones debido a la parcialización de los derechos con los que cuenta la población dominante y la que se ha mal llamado minoritaria. Estos procesos de movilización pueden darse en dos vías: 1) no hay un rechazo al origen y se continúa generando una afirmación personal como miembro de una etnia, a pesar de atesorar otra disposición económica o formativa; y 2) la cara contraria, cuando el individuo no concibe su identidad y emprende desplazamientos para asemejarse a otros individuos (en cierta medida, renuncia a su origen étnico, racial o social ${ }^{13)}$. En cualquier caso, el problema es qué categoría define a alguien cuya piel lo une a la cultura negra, pero en quien no hay

11. Estos riesgos aplican cuando retomamos los planteamientos de una antropología tradicional, como la que hemos mencionado anteriormente, centrada en factores biológicos.

12. Según Darío Henao (2017: 136): “Ekobio: ‘Hermano’ o ‘compañero’. En Changó, el gran putas surge de la necesidad de encontrar una palabra que identificara a los negros sin llamarlos de esta forma. Además, así se identifican los miembros de la secta Abakuá de Cuba”.

13. Esto es lo que ha dado a nombrarse como blanqueamiento: el sujeto dimite de su condición racial para alcanzar beneficios de la sociedad dominante. 
una adscripción con esta población. En tal encrucijada, concierne ver lo negro como un concepto abierto y dinámico que posibilita estudiar y analizar los matices que envuelve lo humano. No se trata de dejar todo a la subjetividad, sino de promover una antropología humanista que cuestione las condiciones por las que atraviesa un individuo para sentirse parte de un grupo. En un principio, categorías como negritud, acotada por Léopold Sédar Senghor, daban respuesta a esa búsqueda de identidad; el concepto

está íntimamente ligado a un proceso de afirmación e identificación con la cultura africana, entendiendo esta como un todo puro. Claro que eso planteado aquí en América no tiene ningún sabor. Y no lo tiene porque las raíces africanas que se buscan ya se transculturaron aquí en el continente. (Zapata-Olivella, 1980)

Líneas más adelante, Zapata Olivella afirma que buscar una afirmación del ser negro debe partir de lo que las generaciones anteriores han recreado en América. Es crucial no asumir una mirada única, sino valorar y posicionar lo étnico como parte integral de nuestra forma de entender y concebir el pasado que corre por nuestras venas; debe promoverse una visión que permita al individuo integrarse a la sociedad, bajo su propia disposición cultural. Y es en ese deconstruir de nociones sobre la etnia o la identidad que la antropología ha vivido una migración de saberes desde aquellos años cuando las personas negras no aparecían en la esfera global, hasta los instantes en que el esfuerzo iniciado por un pequeño grupo de hombres y mujeres reorientó las concepciones sobre la conformación del país. Sus ideas han dejado ver la diferencia de manera positiva y asumir, siguiendo a Fals Borda (1982: 12), lo indígena y lo negro "en un hecho fundamental del desarrollo colectivo".

\section{Fondo Nina S. de Friedemann}

Mi acercamiento a este Fondo se dio a través de Manuel Zapata Olivella ${ }^{14}$, pues a mediados de 2017 buscaba datos sobre el Primer Congreso de la Cultura Negra de las Américas (1977), y en sus archivos me topé con información sobre él, al mismo

14. En mi trayectoria académica he cuestionado que los archivos de Manuel, actualmente en la Jean and Alexander Heard Libraries de la Universidad de Vanderbilt (Nashville-, Tennessee, EE. UU.), no estén en el país (es de valorar que esta universidad ha emprendido un trabajo exhaustivo de su legado y ofrece, por intermedio del Center for Latin American Studies, una beca de investigación para visitar y estudiar su obra). Aunque enunciar los factores que determinaron su ubicación exceden el propósito del texto, remito a las razones anotadas por Pablo F. Gómez (La colección Manuel Zapata, en Revista de Estudios 
tiempo que descubrí un voluminoso trabajo que fue ineludible explorar ${ }^{15}$. La historia del lugar en que terminó su biblioteca suscita experiencias que me permito escribir, no para catalogar su obra, como sí para invitar a estudiar los folios que la integran.

Un año antes de su muerte, en julio de 1997, Nina contactó a Jorge Orlando Melo, entonces director de la Biblioteca Luis Ángel Arango, para coordinar la entrega de unos materiales y crear un fondo que, por deferencia del ilustre historiador, pasaría a llamarse Nina S. de Friedemann. De esta forma entregó varias colecciones de American Anthropologist, Current Anthropology y Ethnology -su edición continúa en la actualidad-, revistas que atestiguan la magnífica biblioteca cuya creación fue motivada por el hecho de no tener fácil acceso a materiales bibliográficos de las universidades. Tras su muerte el 29 de octubre de 1998, a causa de un infarto, la empresa de inventariar, embalar y enviar todo quedó en manos de Greta Friedemann y Jaime Arocha, quienes en 1999 continuaron la labor. Greta define ese momento en los siguientes términos:

La empacada del estudio era surreal... el desensamblar el estudio era casi que impensable. ¿Cómo empacar 40 años de trabajo de un individuo? ¿En qué caja empaca uno la pasión que tenía Nina por su trabajo, por ver justicia social hacia la gente negra colombiana? ¿Y dónde empaca uno el desasosiego e incertidumbre de (...) lo que ocurriría con los materiales? El estudio era un estudio, claro, pero también era un sitio de reunión y conversación y contenía simbólicamente a Nina. El conjunto de personas que venían, casi que a diario era numeroso. Era muy usual el que las reuniones se alargaran y los visitantes ya fuesen estudiantes, académicos nacionales e internacionales, líderes sociales, e individuos de las comunidades sobre las cuales ella escribía se quedaran para almorzar o cenar. (Friedemann-Sánchez, 2018: 2)

En total, entregaron 29 cajas con libros divididos por temas (Caribe, África, América, Colombia negra, antropología, legislación, etnoeducación, publicaciones seriadas), correspondencia, fotografías, material fílmico, cintas de audio, diarios, efímeras (carteles, afiches o plegables que poco se conservan después de realizar un evento y son piezas museográficas únicas); otras novedades fueron mapas del desplazamiento ciudadano en diferentes departamentos, proyectos de investiga-

Colombianos, $\mathrm{N}^{\circ}$ 37: 117-118. 2011), siendo la más importante el desinterés del Gobierno por comprar los materiales. Esta ausencia documental hizo que la serendipia estuviese de mi lado, pues gracias a ella me topé con una obra de la cual resulta este artículo.

15. En la voz de Carmen Millán escuché, por primera vez, el nombre de Nina S. de Friedemann. Mi llegada a su archivo y la investigación sobre Zapata Olivella que terminó con la publicación de Entre Ekobios. Manuel Zapata Olivella (1920-2004). Espacios investigativos: invitaciones al archivo (Millán de Benavides; Rondón-Vélez, 2019), debo agradecerla a su guía como maestra y colega. 
ción, informes del o al ICAN, mensajes de organizaciones sociales a ministerios, secretarías y diferentes estamentos gubernamentales; así mismo, libros para ser reseñados o artículos postulados para publicarse en América Negra.

Todos esos documentos amarillos, con hojas desgarradas y un olor peculiar a causa del amontonamiento, irradian la visión de una mujer que conoció el país a partir del sustrato más esencial: la experiencia personal en lugares donde la relación con la tierra determina las formas de habitar el mundo. Ejemplo de ello es Ma Ngombe: guerreros y ganaderos en Palenque (Friedemann; Cross, 1979), donde se aleja del eclecticismo académico y se deja llevar por relatos de su inmersión en San Basilio de Palenque, apoyada en una estética bella y novedosa que combina fotos de Richard Cross con un minucioso análisis de los rituales, la lengua, la organización y las luchas de aquel sitio (el Fondo conserva los negativos que se descartaron y exhiben el voluminoso trabajo que implicó esa odisea editorial).

Otra constelación son los materiales legales donde sobresalen: la Real Cédula de mayo de 1789, sobre el trato que los amos debían dar a sus esclavos en las colonias españolas; una transcripción de las escrituras de Palenque (escrito vital para sus pobladores, pues les confiere propiedad sobre un zona con la cual tienen una adherencia espiritual y simbólica); decretos y guías del Ministerio de Educación Nacional sobre los lineamientos generales para la etnoeducación (lectura fascinante para deliberar sobre las prácticas educativas que se pensaron y falta promover en colegios y claustros universitarios); una carta dirigida a la Comisión de Paz de 1988 (establecida en Bogotá) que aborda la Guerra de exterminio que vivían los indígenas y la necesidad de incluirlos en los procesos de paz. Un exterminio que se extendió hasta mediados de los noventa con las masacres de Curvaradó, Jiguamiandó, Truandó y demás pueblos del bajo Atrato, como lo denuncia Nina en otra comunicación dirigida al mandatario Ernesto Samper Pizano (1994-1998), donde lo exhorta a proteger estos lugares frente al creciente conflicto ${ }^{16}$.

Los escritos con mayor relevancia legislativa son los borradores, comentarios, extractos y copias de la Ley 70; en ella Nina tuvo un papel protagónico al mediar entre las comunidades y el Gobierno. Como portavoz, envió cartas a los presidentes Julio Cesar Turbay (1978-1982) y Belisario Betancur (1982-1986), y al ministro de Gobierno Humberto de la Calle Lombana (1990-1993), en las que cuestionó el actuar de los ministerios por desconocer los derechos de los afrocolombianos y enfatizó la urgencia de instaurar la Comisión Especial para las Comunidades Negras en 1992; liderazgo seguido por Piedad Córdoba, Silvio Garcés y Rudecindo Castro, para que

16. Algunas noticias que explican las causas, consecuencias y su repercusión en los últimos años se encuentran en el artículo "Condenan a 16 personas por desplazamientos en Jiguamiandó y Curvaradó" (El Tiempo, 2014). 
el Congreso de la República acogiera lo que sería la futura ley. Todo este actuar no pasó desapercibido:

En la noche del 21 de agosto de 1993, cuando en la sede de la Organización de Barrios populares de Quibdó, Obapo, celebrábamos el que el presidente Cesar Gaviria (1947-), quien gobernó entre 1990-1994, hubiera firmado la que más adelante se denominaría Ley 70 de 1993 o "Ley de negritudes", esos líderes comunitarios reiteraran que la obra de Friedemann les había inspirado sus reivindicaciones. (Arocha, 2006:349-350)

El rigor para recopilar información demostró que incorporar la voz de las personas en los escritos que pretendían analizarlas tenía efecto en las políticas públicas. En el plano académico, Nina aportó en la creación de la cátedra de estudios afroavenezolanos en el Instituto Venezolano de Investigaciones Científicas, fundado en 1959; además, participó en la fundación de la Sociedad Antropológica de Colombia, a finales de 1960, y de la Unión Nacional de Escritores; fue miembro de la Asociación Antropológica Americana y de la Sociedad para la Antropología de la Comunicación Visual, títulos que le valieron la nominación por Colombia para el premio Gabriela Mistral de la Organización de Estados Americanos en 1987 (Biblioteca Luis Ángel Arango [BLAA], 2018b).

A lo largo de su vida, Nina entabló amistad con escritores y directivos de institutos o facultades ${ }^{17}$. Es así que existe variada correspondencia sobre las ideas que han marcado los estudios culturales en diversas latitudes. Aunque, como señala Debra D. Andrist, las relaciones masculinas han gozado de mayor atención y el retrato de hombres como amigos y su relación como escritores es relevante en la formación del canon, en Amistades masculinas versus amistades femeninas en Don Quijote expone que las relaciones epistolares de las mujeres han tenido menos importancia, pero "estas pueden ofrecer no solo mayor información sobre sí mismas, sino que también pueden iluminar las relaciones masculinas" (Andrist, 1983: 149). En este sentido, diálogos con Abdias do Nascimento o Norman Whithen, y sus lazos con los hermanos Zapata Olivella ${ }^{18}$, abrigan mensajes que explican cómo surgieron sus

17. El Fondo tiene documentos originales (primeras versiones y correcciones manuscritas) de artículos que Theodore Nichols, James J. Parsons, Muhammad Anisur Rahman, Armando Silva, Marvin Lewis, Ian I. Smart, Jhon M. Lipski y otros enviaron con el fin de publicitar su trabajo o conocer apreciaciones sobre él.

18. Delia, fundadora del Instituto Folclórico Delia Zapata Olivella, quien consolidó las danzas y muestras folclóricas nacionales; y Juan, embajador de Colombia en Haití, candidato a la presidencia para el período 1978-1982 por el Movimiento de las negritudes y el mestizaje; escritor que en la vía de su hermano Manuel acrecentó la presencia Caribe en la zona céntrica de Colombia. 
libros, qué luchas cursaron en su país natal en el ascenso intelectual o cómo crearon plataformas de difusión iberoamericanas.

Otro prodigio del Fondo es la antropología visual; en su trabajo con las comunidades Nina produjo las películas (filmaciones en súper $8 \mathrm{~mm}$ y $16 \mathrm{~mm}$ ): Güelmambi (1974), Villarrica (1974), Ríos de oro (1975) y Congos (1977); piezas de cine donde se proyectan actividades diarias en caseríos, corregimientos y otros territorios, con una narración sencilla. Adelantada a su época, expuso sus hallazgos a los sujetos que le posibilitaron obtenerlos, dejándolos a su valoración, para después, a partir de sus comentarios, modificar las inconsistencias. Gracias a esa labor de investigar observando es que se da De sol a sol (1986), "volumen integrado por treinta y nueve cuentos sin ficción, sencillos y directos, sin oropeles ni divertimentos marginales, en torno al más infernal e irracional de los dramas de la historia moderna: la esclavitud africana" (Díaz-Granados, 1986: 11).

Herederos del jaguar y la anaconda (Friedemann; Arocha, 1982), es un ejemplo más de estética prodigiosa que fusiona imagen y texto con mitos o rituales. Concebido expresamente como una obra de divulgación del acontecer indio, se sacan la etnografía y ensayos fotográficos de los entornos especializados, en medio del Estatuto de Seguridad (1979) de Julio César Turbay (normatividad represiva que puso en riesgo la territorialidad ancestral), para representar una invaluable imagen de la Colombia aborigen. Conforme se aprecia en cada capítulo, el libro:

No solamente es un esfuerzo por difundir el gran fenómeno cultural indio en Colombia. El volumen se presenta en el escenario de defensa de la indianidad por la que los mismos indios de América luchan actualmente. La indianidad, entendida como una opción de los pueblos aborígenes a vivir y mantener sus instituciones y cultura, hace parte del ejercicio de derechos humanos cuya presencia o ausencia definen la democracia de las naciones contemporáneas. (Friedemann; Arocha, 1982: 21).

Con todo lo dicho, es claro que "la carrera de Nina no ha terminado, ya que sus (...) publicaciones y manuscritos inéditos continúan estando a la vanguardia, dando lecciones y dejando legados" (Friedemann-Sánchez, 2018: 7). Para mí, asiduo navegante del Fondo, no es fácil concebir su magnitud; por ello declaro su importancia para que investigadores y editores dirijan su atención a él y se comprometan a desarrollar trabajos que aclaren los sucesos históricos allí presentes, con el objetivo de avanzar en la justicia social. 


\section{Conversaciones: 20 años sin Nina}

El 29 de octubre de 2018 se cumplieron 20 años del fallecimiento de Nina. Distanciados del período en que consolidó su producción, colegas y familiares aunaron esfuerzos para recordarla ${ }^{19}$. Aunque fue complejo advertir la envergadura de su legado, el evento no se resignó al recuerdo y apostó por actualizar su obra colocándola en escenarios de debate que dieran a conocer lo que aportó a la antropología moderna $\mathrm{y}$ cómo sus conceptos han mutado, en busca de mayor especificidad ${ }^{20}$. Una de esas conexiones la expresó Alberto Abello en las palabras inaugurales, al manifestar el impacto que tuvo en sus proyectos personale ${ }^{21}$ :

Cuando murió Nina, acabábamos de inaugurar en Cartagena el observatorio del Caribe Colombiano, y (...) para los que no éramos antropólogos, fue una obligación sentarnos a estudiarla, porque una entidad como esta (...) que pretendía estudiar las posibilidades de transformación socio-económica de la región, no lo podía hacer sino comprendía las matrices culturales de ella, especialmente en una región como el Caribe colombiano. Y Nina nos enseñó mucho sobre el Caribe, realmente muy pocas personas entendían que hablar de sociedad, economía y cultura, debería hacerse en los mismos planos (...). Sus trabajos sobre el carnaval son una pieza fundamental en la comprensión no solamente de esta práctica cultural, sino en la comprensión de una región, de la red, las relaciones, las migraciones, las diásporas, los movimientos que se generan alrededor de los carnavales.

19. El evento hizo parte de la celebración de los 60 años de la BLAA, en el marco de un programa institucional enfocado en destacar las trayectorias intelectuales de la mujer en Colombia (BLAA, 2O18b).

20. Los ponentes del evento fueron: Greta Friedemann, profesora asociada del Humphrey School of Public Affairs, University of Minnesota (EE. UU.); Robert Friedemann; Nancy Friedemann, artista plástica; Graciela Maglia, profesora-investigadora del Instituto Caro y Cuervo, y coordinadora de la Cátedra de Herencia Africana; Ramiro Delgado Salazar, profesor de Antropología, Universidad de Antioquia; Laura Correa Ochoa, candidata a doctora del Afro-Latin American Research Institute at the Hutchins Center, Harvard University (EE. UU.); Jaime Arocha, profesor-investigador, fundador del Grupo de Estudios Afrocolombianos, Universidad Nacional de Colombia.

21. Al escribir estas líneas, la noticia de su muerte me conmueve. El país despide un académico preocupado por ampliar nuestras miradas sobre el Caribe, en libros como Los desterrados del paraíso. Raza, pobreza y cultura en Cartagena de Indias (2015) o La isla encallada. El Caribe colombiano en el archipiélago del Caribe (2015). Durante el evento, concretado mientras dirigía la Red de Bibliotecas del Banco de la República, me contó que trabajaba en una publicación sobre los carnavales, estudio que nutrió con documentos y películas de Nina -Congos, por ejemplo, la cual analizó y comentó en la cuarta jornada del encuentro, o Fiestas: celebraciones y ritos en Colombia (Friedemann; Horner, 1995), donde se recopilan los carnavales de diferentes regiones colombianas, y enriquecido con las imponentes y coloridas fotografías de Jeremy Horner-. Lo aquí escrito no puedo más que dedicarlo a su memoria. Un hombre con el cual quedé en deuda de tomar un café para conversar. 
IMAGEN 2 Nina S. de Friedemann (1985)

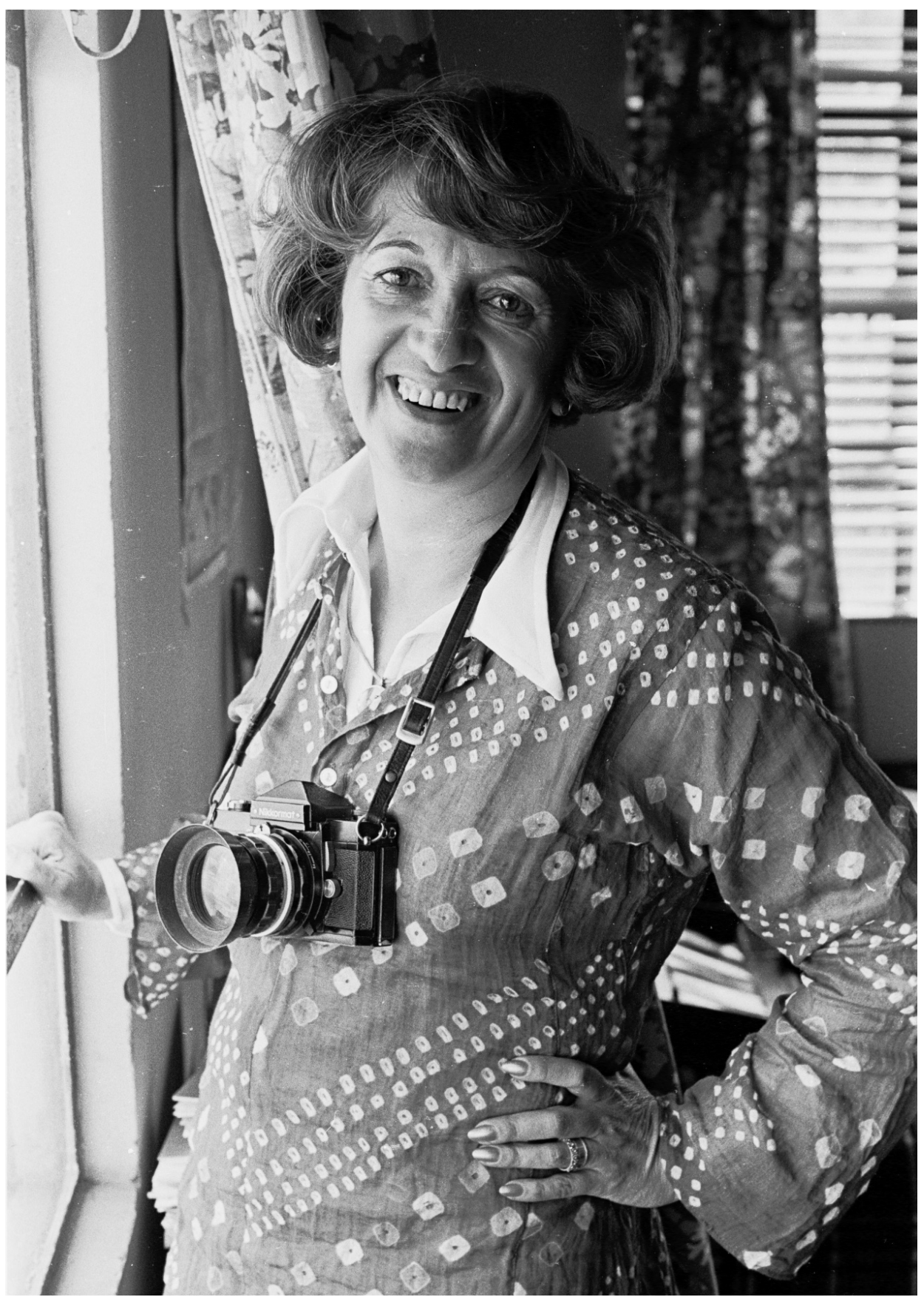

Foto: (C) Robert Friedemann. Archivo Familiar Friedemann-Sánchez (Bogotá, Colombia) 
En la primera jornada, Greta Friedemann-Sánchez presentó la conferencia Ética en el ejercicio profesional: el legado de Nina S. de Friedemann; allí propuso los lineamientos que caracterizaron el proceder de su madre y antepuso la importancia que tuvo no concebir a las personas como objeto de estudio, sino como sujetos acreedores de una cultura que despertaba su curiosidad. Con un énfasis en cómo los investigadores pueden respetar y velar por el correcto tratamiento de la información de quienes estudian, sus palabras dieron una imagen del proceder metodológico que debe habitar las ciencias sociales.

La presentación El fondo Nina S. de Friedemann, de Jaime Arocha, brindó un acercamiento íntimo a los tesoros que esconde esta colección; él -quien hizo parte de los viajes y discusiones de salón que nutrieron varios libros-trazó los caminos que recorrió en compañía de su maestra y mostró los cambios que ha tenido Colombia en su composición cultural y territorial. Sus palabras fueron la antesala a la segunda jornada, cuando los asistentes interactuaron con una parte de los documentos que integran el Fondo: fotos de Palenque tomadas por Nina y Richard Cross, donde se muestran los grupos de edad o los rings de pelea entre niños y niñas; informes del Primer Congreso Nacional de Cultura, los congresos de la Cultura Negra de las Américas - celebrados en Cali (1977), Panamá (1980) y São Paulo (1982)-; o el cuento La entrevista (también existe Los platos rosa), desconocido en los formatos de escritura característicos de la bogotana, donde cuestiona el actuar de una ministra que siempre dice "Dígame, lo estoy escuchando", pero nunca parece conocer los problemas del pueblo o siquiera intentar resolverlos (retrato semejante a ciertos estratos del poder que no escuchan otras voces y se aferran a posiciones cerradas; muy cercano a lo que sucedía durante el período crítica y conflicto).

Durante la tercera jornada, el 30 de octubre, Ramiro Delgado Salazar presentó Nina S. de Friedemanny sus imágenes sobre África y sus huellas de africanía en Colombia. Metodologías, aportes y sentidos actuales, conferencia en la cual recordó cómo en sus viajes a Palenque siempre lo acompaña Ma Ngombe, libro que ha colgado a modo de galería sobre las paredes del pueblo para generar conmociones en la gente que observa su pasado guerrero. Otra de las ponentes, Laura Ochoa, encausó su charla a De sol a sol en los archivos de Nina de Friedemann: en busca de una nueva mirada sobre raza, nación y activismo indígena y afrocolombiano en el siglo $X X$, y manifestó cómo gracias a Nina se dieron nuevas concepciones de lo humano. Finalmente, durante la última jornada se proyectaron y comentaron cuatro películas, una muestra de la antropología visual que amplió las formas en que se desarrollaba la etnografía durante el siglo XX. El evento culminó con la proyección de algunos fragmentos de una entrevista que la Universidad Nacional de Colombia hizo a Nina en 1995; breves imágenes que trajeron de nuevo, al menos en su voz, a la mujer que se convirtió 
demasiado pronto en argonauta del firmamento. Durante las cuatro jornadas, ante la cantidad de información que correspondía nombrar y conocer, los espacios de la BLAA estuvieron habitados por "niños sorprendidos, como en una tienda de dulces" (analogía con la cual Ramiro Delgado Salazar describió su emoción).

Partiendo de la metáfora empleada por Greta para sintetizar los 68 años de su mamá, aquellos días de octubre se vivieron "como una vela en el viento: quemándose rápida e intensamente". Cada presentación, tocada por la nostalgia de homenajear a una mujer que murió joven, dio cuenta de un trabajo que se extendió por 40 años. Las conversaciones analizaron, entre muchos temas, las manifestaciones artísticas caribeñas que gozan de relaciones destacables con la gente africana del Kikongo, por los rastros que las indumentarias de ese pueblo dejaron en los vestidos de los congos del Carnaval de Barranquilla. Al respecto, destaco una carta que Nina envió, el 15 de agosto de 1984, desde Senegal, a Jaime Arocha:

Todas mis expectativas sobre este continente eran más cortas y limitadas que la realidad (...). La riqueza cultural extraordinaria. El alma de África, pese a la colonización está aquí. Nuestros negros tienen apenas una sombra de esta civilización, pero me sorprende que después de 500 años aún mantengan esa sombra. Cierro los ojos que ven a África y veo en Colombia mucho de este continente en la habitación. Las cortinas de tela dividiendo los cuartos, las empalizadas, las mujeres lavando y cantando los sonidos que hacen como de admiración, el estilo de comer [son los del Pacífico]. (Arocha, 2006 342)

Algunas frases pronunciadas durante el evento pusieron de relieve cómo Nina, lejos de los reflectores académicos, concilió su papel de esposa y profesora (en varias oportunidades de la Universidad Nacional de Colombia, al igual que docente visitante en EE. UU. con la beca Fulbright-Hays), con el de investigadora, etnógrafa y mecenas (Robert Friedemann, por ejemplo, mencionó curiosas anécdotas de cuando Antonio Cervantes Reyes, más conocido como Kid Pambelé, vivió con ellos). En tanto coordinador del evento, es para mí una labor casi metafísica rememorar cada instante, porque después de leer durante dos años páginas donde se nombraba a multitud de personas, en 48 horas debí asignar rostros a algunos nombres.

En 20 años sin Nina, la Biblioteca Luis Ángel Arango abrió oficialmente el archivo al público; qué mejor momento para hacerlo que entre las remembranzas de una vida pasada. Tal labor significó una catarsis para Greta, abrir aquel cosmos evocó sentimientos que comparto en síndrome claro de la conmoción que he sentido leyendo su obra: "Todo individuo que haya vivido la muerte de un ser amado entiende y tiene empatía con el desasosiego logístico y emocional que sigue tras el evento" (Friedemann-Sánchez, 2018: s.p.). Llegados los renglones finales de este recorrido, 
no puedo dejar de manifestar un principió que pernotó en Nina y el cual resulta esencial para estudiantes y profesionales de la antropología: emprender investigaciones responsables en las que comprendan su labor como trabajadores de justicia social; tal cual anotó en Antropólogos y antropología en Colombia: sus responsabilidades (1971), ellos tienen el menester hacia el público de diseminar los resultados de sus análisis y de dejarles saber sus opiniones como estudiosos del hombre.

Por último, es justo puntualizar que no basta con proclamar celebraciones o pronunciar nombres en los congresos y consignarlos en sus carteles; a veces, estas acciones tan solo son actos simbólicos de poder y dejan a un lado aquello que se traslapa en los ejercicios intelectuales. Al recordar un autor debemos preguntarnos por el sentido de su obra, el proceso creativo que llevó a ella, indagar por lo impensado, por aquellos dispositivos que habita, inventa o interviene. En otras palabras, es preciso trascender la actitud esnobista de mencionar un autor cuando se acerca la celebración de su natalicio o muerte; nos corresponde alentar y exigir políticas públicas que se preocupen por difundir la producción académica colombiana. Es necesario fortalecer las becas de investigación, leernos; ya se emprendieron muchos estudios sobre grandes autores, ahora toca abrir el abanico a otros que no han tenido suficiente atención. Este artículo invita a pensar que el reto no debe estar en adquirir condiciones económicas para salvaguardar los documentos-eso debe ser inherente al estudio mismo de los archivos-, sino en posibilitar el acercamiento a la obra de quienes gestionaron un trabajo que luchó por alcanzar la justicia social y el reconocimiento de la diferencia como sustancia originaria de nuestra identidad.

\section{Referencias}

Andrist, Debra D. (1983). Male versus Female Friendship in "Don Quijote”. Bulletin of the Cervantes Society of America, 3(2), 149-159.

Arocha, Jaime (1984). Antropología en Colombia: una visión. En Un siglo de investigación social. Antropología en Colombia (pp.381-429), editado por Jaime Arocha; Nina S. de Friedemann. Bogotá: ETNO.

Arocha, Jaime (2006). Nina S. de Friedemann (1930-1998). En Pensamiento Colombiano del siglo XX (Tomo II) (pp.339-371), editado por Guillermo Hoyos-Vásquez; Carmen Millán de Benavides; Santiago Castro-Gómez. Bogotá: Pontificia Universidad Javeriana.

Biblioteca Luis Ángel Arango (2018a). 20 años sin Nina. Recuperado de http://www. banrepcultural.org/noticias/20-anos-sin-nina 
Biblioteca Luis Ángel Arango (2018b). Nina S. de Friedemann. Recuperado de http://enciclopedia. banrepcultural.org/index.php/Nina_S._de_Friedemann

Condenan a 16 personas por desplazamientos en Jiguamiandó y Curvaradó (15 de diciembre de 2014). El Tiempo. Recuperado de https://www.eltiempo.com/archivo/documento/ CMS-14980958

Díaz-Granados, José L. (1986). Dos antropólogos cuentan cuentos sin ficción. En De sol a sol. Génesis, transformación y presencia de los negros en Colombia (pp. 11-12). Bogotá: Planeta.

Delgado-Salazar, Ramiro (octubre, 2018). Nina S. de Friedemann y sus imágenes sobre África y sus Huellas de Africanía en Colombia. Metodologías, aportes y sentidos actuales. Ponencia presentada en Conversaciones: 20 años sin Nina, Bogotá, Colombia.

Escalante, Aquiles (1980). Historia de la Antropología colombiana. Entrevistadora: Nina S. de Friedemann. América Negra. Inédito.

Fals-Borda, Orlando (1982). Prólogo. En Herederos del jaguar y la anaconda (pp. 9-12), editado por Nina S. de Friedemann; Jaime Arocha. Bogotá: Carlos Valencia Editores.

Friedemann-Sánchez, Greta (2018). Ética en el ejercicio profesional: el legado de Nina S. de Friedemann. Inédito.

Friedemann, Nina S. de (s.f.). En los terrenos de la diáspora afrocolombiana. Inédito.

Friedemann, Nina S. de. (1964-1965). Ceremonial religioso funébrico representativo de un proceso de cambio en un grupo negro de la Isla de San Andrés (Colombia). Revista Colombiana de Antropología, XIII, 147-182.

Friedemann, Nina S. de (1965). Tenencia de tierras, un factor de marginación socioeconómica en una comunidad rural. El común de indígenas en Churuguaco. Revista Colombiana de Antropología, 13, 267-286.

Friedemann, Nina S. de (1967). Miss Nansi, Old Nansi y otras narraciones de folklore de la Isla de San Andrés (Colombia). Revista Colombiana de Folclor, 4(9), s.p.

Friedemann, Nina S. de. (1969). Güelmambí: Formas económicas y organización social. Revista Colombiana de Antropología, XIV, 53-78.

Friedemann, Nina S. de (1971). Antropólogos y antropología en Colombia: sus responsabilidades. Revista de la Universidad Nacional, 9, 5-16.

Friedemann, Nina S. de (1974). Minería, descendencia y orfebrería artesanal litoral pacífico (Colombia). Bogotá: Universidad Nacional de Colombia.

Friedemann, Nina S. de (1978a). Entrevista a Nina de Friedemann sobre las ideas contenidas en el artículo: Estereotipia y realidad de la identificación del negro colombiano. Entrevistador: Jaime Arocha. América Negra, 16. Inédito. 
Friedemann, Nina S. de (octubre, 1978b). Una aproximación a la bibliografía antropológica sobre grupos negros en Colombia. Ponencia presentada en Primer Congreso Nacional de Antropología en Colombia, Popayán.

Friedemann, Nina S. de. (1980). Estereotipia y realidad en la identificación del negro colombiano. Ponencia presentada en el II Congreso de la Cultura Negra de las Américas. Panamá, Panamá.

Friedemann, Nina S. de (1984). Ética y política del antropólogo: compromiso profesional. En Un siglo de investigación social. Antropología en Colombia (pp. 381-429), editado por Jaime Arocha; Nina S. de Friedemann. Bogotá: ETNO.

Friedemann, Nina S. de (1987). Antropología en Colombia: después de la conmoción. Revista de Antropología, 3 (2), 142-164.

Friedemann, Nina S. de (1994). Vida y muerte en el Caribe afrocolombiano: cielo, tierra, cantos y tambores. América negra, 8, 83-96.

Friedemann, Nina S. de; Arocha, Jaime (1979). Bibliografia anotada y directorio de antropólogos colombianos. Bogotá: Sociedad Antropológica de Colombia. Bogotá: Tercer Mundo Editores.

Friedemann, Nina S. de; Arocha, Jaime (1982). Introducción. En Herederos del jaguar y la anaconda (pp. 13-30). Bogotá: Carlos Valencia Editores.

Friedemann, Nina S. de; Arocha, Jaime (1984). Un siglo de investigación social. Antropología en Colombia. Bogotá: ETNO.

Friedemann, Nina S. de; Arocha, Jaime (1986). De sol a sol. Génesis, transformación y presencia de los negros en Colombia. Bogotá: Planeta.

Friedemann, Nina S. de; Arocha, Jaime (1991). De los editores. América Negra, 1, 4-6. Recuperado de https://www.javeriana.edu.co/documents/5782625/5900951/AmericaNegra1. pdf/3b414153-7c91-49e9-bd3e-aoa5f135de93

Friedemann, Nina S. de; Cross, Richard (1979). Ma Ngombe: guerrerosy ganaderos en Palenque. Bogotá: Carlos Valencia Editores.

Friedemann, Nina S. de; Horner, Jeremy (1995). Fiestas: celebraciones y ritos de Colombia. Bogotá: Villegas Editores.

Friedemann, Nina S. de; Patiño-Rosselli, Carlos (1983). Lengua y Sociedad en el Palenque de San Basilio. Bogotá: Instituto Caro y Cuervo.

Gómez, Pablo F. (2011). La colección Manuel Zapata. Revista de Estudios Colombianos, 37, 117-118.

Henao-Restrepo, Darío (2017). El código Changó: los misterios del Muntu. En Manuel Zapata Olivella al encuentro con la diáspora. Memorias (pp. 61-97). Bogotá: Delfín. 
Mallol de Recasens, Rosa M. (1967). Dibujo infantil y personalidad cultural en la isla de San Andrés (Colombia). Revista Colombiana de Antropología, 13, 183-214.

Millán de Benavides, Carmen; Rondón-Vélez, Peter (2019). Entre Ekobios. Manuel Zapata Olivella (1920-2019). Espacios investigativos: invitaciones al archivo. Bogotá: Instituto Caro y Cuervo.

Mintz, Sidney W. (1996). Dulzura y poder. El lugar del azúcar en la historia moderna. México: Siglo XXI.

Muñoz-Vásquez, Martha (1995). Historia debida: Nina S. de Friedemann [documental]. Universidad Nacional de Colombia. Recuperado de https://www.youtube.com/ watch?v=SolKUujLlOU

Patiño-Rosselli, Carlos (1999). Nina la palenquera. Inédito.

Restrepo, Camila; Ramírez, Santiago; Murcia, Luis (2019). Líderes sociales en Colombia: ¿quién los está asesinando? Revista Semana. Recuperado de http://especiales.semana. com/lideres-sociales-asesinados/index.html

Restrepo, Eduardo (2013a). Acción afirmativa y afrodescendencia en Colombia. En Estudios afrocolombianos hoy: aportes a un campo transdisciplinario (pp. 249-266). Popayán: Universidad del Cauca.

Restrepo, Eduardo (2013b). Introducción. En Estudios afrocolombianos hoy: aportes a un campo transdisciplinario (pp. 7-18). Popayán: Universidad del Cauca.

Spivak, Gayatri Chakravorty (1998) ¿Puede hablar el sujeto subalterno? Orbis Tertius, 3 (6), 175235. Recuperado de http://www.memoria.fahce.unlp.edu.ar/art_revistas/pr.2732/pr.2732. pdf

Viveros-Vigoya, Mara (2013). Mestizaje, trietnicidad e identidad negra en la obra de Manuel Zapata Olivella. En Estudios afrocolombianos hoy: aportes a un campo transdisciplinario (pp. 87-105), editado por Eduardo Restrepo. Popayán: Universidad del Cauca.

Wade, Peter (2013). Definiendo la negridad en Colombia. En Estudios afrocolombianos hoy: aportes a un campo transdisciplinario (pp. 21-41), editado por Eduardo Restrepo. Popayán: Universidad del Cauca.

Zapata Olivella, Manuel (1980). El libro de un africano blanco. Entrevistadora: Nina S. de Friedemann. El Espectador. 